\title{
A Simulation Approach to the Design and Evaluation of Auditory Interfaces in a High Speed Train Driving Cab.
}

\author{
Peggy Zwolinski \\ Institut Polytechnique de Sévenans. L’Université de Technologie de Belfort-Montbéliard \\ 90010 BELFORT cedex (FRANCE) \\ Phone : 03-84-58-31-61 - Fax : 03-84-58-31-41 - E-mail : Peggy.zwolinski@utbm.fr \\ Jean-Claude Sagot \\ Institut Polytechnique de Sévenans. L’Université de Technologie de Belfort-Montbéliard \\ 90010 BELFORT cedex (FRANCE) \\ Phone : 03-84-58-30-13 - Fax : 03-84-58-31-41
}

\begin{abstract}
As operators are spending more and more of their time monitoring and using control systems, auditory displays are becoming increasingly useful along with other control devices and control panels. This paper presents a method, elaborated with the help of engineers, ergonomists and train drivers, for designing and evaluating auditory interfaces for use in high speed train driving cabs. During this design project, ergonomists studied the usefulness and the usability of auditory signals, in relation to visual displays and future driving cab control devices. To take into account every aspect of auditory signals, members of the project have chosen to use a simulation approach benefiting from co-operation between ergonomists, engineers and volunteer train drivers who took part in the entire project for the design of the future driving cab.
\end{abstract}

\section{Introduction}

In the future, trains will travel at $350 \mathrm{~km} / \mathrm{h}$ or more and will run on a European network of high speed tracks. In order to attain such performance, the design of high speed train driving cabs (control panels, informational devices and control devices) needs special attention, as mentioned by Foret [5]. Among the various informational devices, auditory signals play an important role in attracting attention and giving information to the train driver. There are many situations in which a train driver will use sounds e.g. when changing speed, to diagnose malfunctions, to receive a call from another operator, etc. These sounds are used because of the important visual load induced by the demands of the exterior environment (the railway and track signalling). But the extension of the train network throughout Europe, and the evolution of technologies have led to a growing number of different systems in trains and consequently of the different sounds generated. So, particular attention should be given to designing a coherent set of auditory signals for the future taking into account problems of redundant signals and distracting factors which could lead to signal vigilance errors, as demonstrated by Haga [6].

The aim of this paper is to illustrate a pragmatic methodology used to create a more efficient auditory system for the French high speed train driving cab. This is a first step in a study which will eventually include all the sounds used in all European trains. The intent of the paper is not to discuss the technical aspects of sound in high speed trains but to present a user-centred approach using simulation to create auditory interfaces for the future high speed train driving cab.

The first section of this paper concentrates on existing sounds in the driving cab. It is the first stage in the simulation approach because we can build an accurate model of the present situation of auditory signals to determine the model of the future situation. In the second section we will show how to design a system in a co-operative approach using scenarios and by analysing the functions of each sound. In the final part of the paper, we will show how the twelve train drivers who have participated in the entire project have validated on a simulator the set of auditory signals they finally chose.

\section{Analysis of Existing Sounds}

The first step in this study was to make an ergonomic evaluation of existing sounds during the driving activity. Indeed, this analysis of the driving activity is very important to identify factors for improving or for transforming existing working conditions and thus design a man-machine interface. In the present study concerning auditory interfaces, we first of all identified and recorded the 23 sounds being used at present in French train driving cabs. Then we evaluated, according to Momtahan et al. [10], the different sounds. 
Twelve train drivers had to answer a questionnaire and then were tested for their detection and their comprehension of the various sounds.

Next, with reference to Patterson [12], we examined the overall level, the temporal characteristics, the spectral characteristic and ergonomic aspects of each sound. It appears that the main problems of current auditory interfaces are : the sounds are too loud, the temporal patterns are not sufficiently distinctive and the ergonomics of existing auditory systems are deplorable.

For example, let us examine the sounds which trigger an emergency stop. These sounds are defined as follows in the manufacturer's specifications :

radio alarm : continuous buzzer $-1400 \mathrm{~Hz}-1800 \mathrm{~Hz}$ (sound 1).

false start :repeated bell rings (sound 2).

passenger alarm : buzzer - $1000 \mathrm{~Hz}$ - generated $5 *$ [0.25 second $\mathrm{ON}$ and 0.75 second OFF] (sound 3).

As no data was provided in the manual concerning the level of each sound and no recommendation was given concerning a general level, we took various readings inside several driving cabs. We were confronted with a wide variety of results (level, frequency, time,...) for one alarm, depending on which cab we were taking the measures in. It was clear that each generation of locomotive has its own sound generator and that even when the sounds seemed the same, there were differences between each cab.

Concerning the actions to be taken when the sound is played, we noted that drivers must make an emergency stop if they hear a radio alarm, a passenger alarm when starting in a station, or there is a false start from the master controller. But if they receive the passenger alarm in case of SAI (Interphone Alarm System) during the trip (sound 2) they must continue driving until they have more information concerning the incident. So, for the ergonomics of existing auditory systems, most of the problems derive from the fact that new control systems have been installed without a global ergonomic view of the whole system. For example, one sound may require the driver to take three different actions and one action may be required by different sounds. There are no priorities between sounds, so the driver could be called for nothing at any moment even if there is a sudden emergency.

To maximise the effect of ergonomic principles, it's important to review the whole warning system to prevent warnings from proliferating. One way to do this is to establish a warning philosophy and define categories of action urgency [2]. So, we have defined with train drivers the following sound classifications:

* Class 1 : Sounds indicating information to the driver.

* Class 2 : Sounds indicating changes in signalling to the d river.

* Class 3 : Sounds to warn the driver and which require immediate action.

* Class 4 : Sounds to warn the driver to make an emergency stop (danger or an accident).

All these considerations have led us to determine, during the preliminary study, what we have called, according to Sagot et al. [14], "the field of desirable future activities " concerning auditory interfaces, desirable in terms of safety, comfort and efficiency.

\section{Preliminary Study for the Design of Auditory Interfaces}

\subsection{Definition of the Field of Desirable Future Activities}

To define the field of desirable future activities, we have worked with twelve train drivers in order to determine what happens when a sound is made. In principle, acoustic signals have to meet 3 criteria to be effective. The recipient has to detect the signal, to interpret the signal and to take an appropriate action [8]. So, we have defined scenarios about what can happen before, after and at the moment when the sound is played and suggest a general scenario. On the basis of the general scenario (Figure 1), we have chosen to design and evaluate sounds keeping in mind these 3 classes of criteria : detection, comprehension, utility. 


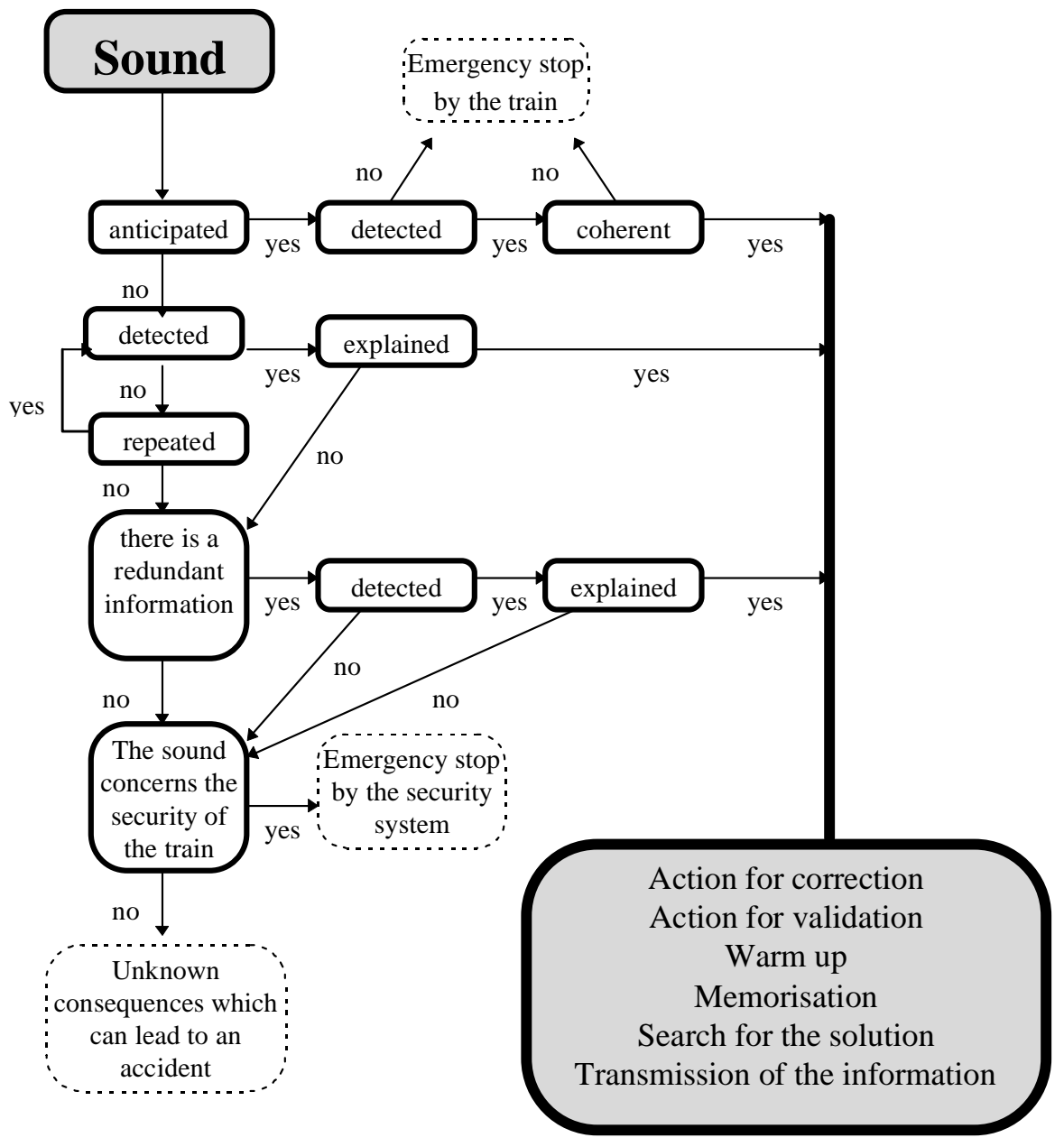

Figure 1 : General scenario concerning what happens when a sound is generated.

\subsection{Functional Specifications of Sounds}

In order to take into account every aspect of the auditory signal in relation to the environment, we have analysed, according to the NF X 50-151 [11], the function of each sound as shown Figure 2.

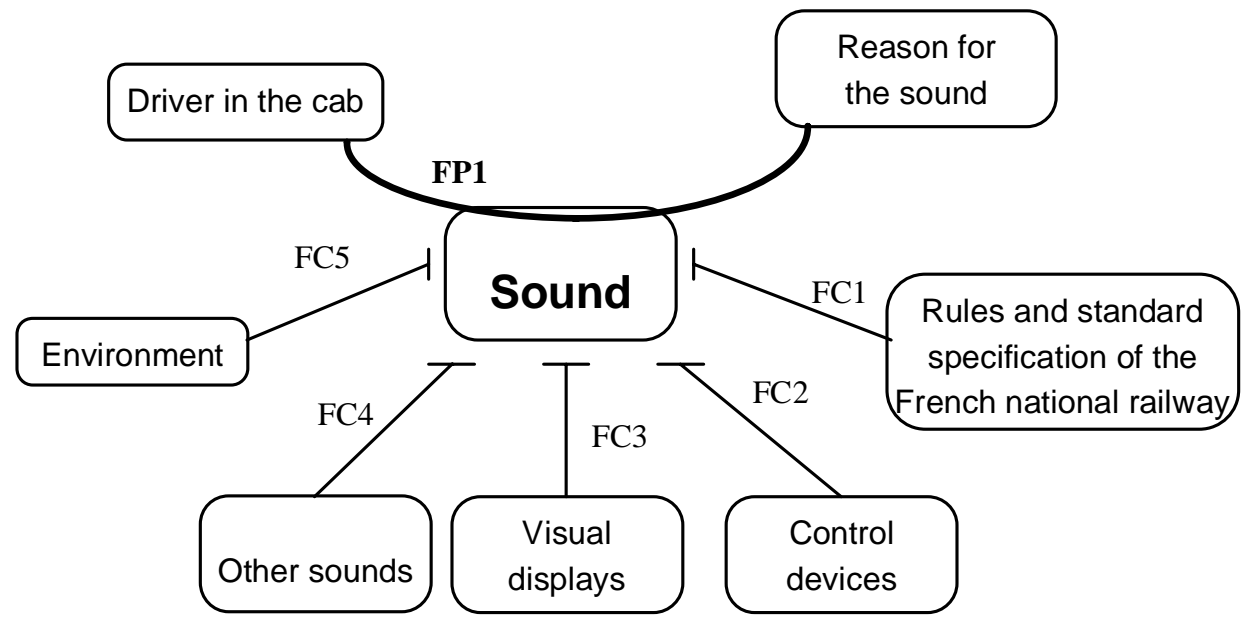

Figure 2 : Example of the functional diagram (FP : principal function - FC : constraint function)

We have identified all the relations between a sound and the elements of its environment. For each relation we can define a function that the sound had to realise and for each function we have made a list of criteria to detail the level of satisfaction concerning each function. With this analysis, we have validated the usefulness of 10 different sounds of the present 23 sounds and given a list of criteria taking into account every aspect of each sound. 


\subsection{Design and First Evaluation of Sounds Concept}

Based on functional analysis, we have built different sounds for the 10 classes of auditory signals. As a wide variety of acoustic parameters have clear and consistent effects on the perceived urgency [7], we have developed 5 or more different non verbal propositions for each sound. All these propositions meet the criteria defined during the functional analysis. To create them, we simply chose sounds with dominant frequencies $(340,400,425,440,500,554,750,900,1000,1100,1260,1400,1520,1800,2000,2500,3000,3250 \mathrm{~Hz})$. We then associated these different sounds with the PC to generate a large number of propositions. We have also used different sounds like buzzers, bells, etc., that we found in sound libraries.

But, as we have noticed, increasing the number of sounds could require an inordinate amount of training and retraining to maintain a perfect identification by all the drivers. So we have suggested that voice warnings should be introduced to reduce the number of sounds required on the train and we have also proposed 2 or 3 messages for each class of auditory signals.

Next, we developed a testing bench to test auditory signals in the noise environment of a cab which we have simulated with real recorded sounds. We generated three environmental sounds (we did not include the sounds from auxiliary equipment which are not continuous and are not very loud.) : Rail rolling sounds Aerodynamic sounds - Electric motor sounds.

To generate the different alarms and the environment, we used :

* A DX 2/50 PC computer with a GRAVIS ULTRASOUND Max card, to generate the interactive sound of the environment and to play the alarm.

* An EXPELEC MIX 003, for mixing the different sounds and to easily adjust the different of sound levels.

* A MARANTZ PM-43 amplifier, with 2 JPW loudspeakers for the environment sound and one for the alarm.

As mentioned by Antin et al. [1], who are working in the automotive sector, it is necessary to use a testing bench to test auditory signals in the environment noise of a cab, to test the appropriateness of the sound level in the environment. According to Fidell [4], it is one of the most efficient ways to validate whether or not the user is able to detect the signals. So, drivers have listen to the different propositions in the sound environment. Then they have to chose between a verbal or non verbal auditory signal and to select the sound they prefer. During their selection, they made a large number of suggestions for optimising the different propositions concerning each sound.

In Table 1 are shown the principles of the solutions retained by the majority of the drivers and validated by all the participants in the project. For each of the final 10 sounds retained, we have determined the type of auditory information (sound or vocal) and if the driver needed a redundant visual information.

\begin{tabular}{|c|c|c|c|c|}
\hline Auditory information concerned & Class & Type & $\begin{array}{c}\text { Visual } \\
\text { information }\end{array}$ & Message \\
\hline radio alarm & 4 & sound & yes & Emergency stop \\
\hline passenger alarm (at start) & 4 & sound & yes & Emergency stop \\
\hline false start & 4 & sound & yes & Emergency stop \\
\hline excess speed alarm & 3 & sound & yes & 1. Speed exceeded \\
Y. You may be stopped
\end{tabular}

Table 1 : Principles retained on solutions by the 12 drivers concerning each sound. 


\section{Evaluation of Auditory Interfaces Using a Simulator}

On the basis of the first evaluation, we have selected and optimised auditory signals for their evaluation in a simulated context. Each volunteer driver has to select a set of sounds before the simulation to evaluate his own choice during a scenario on a simulator ( Figure 3).

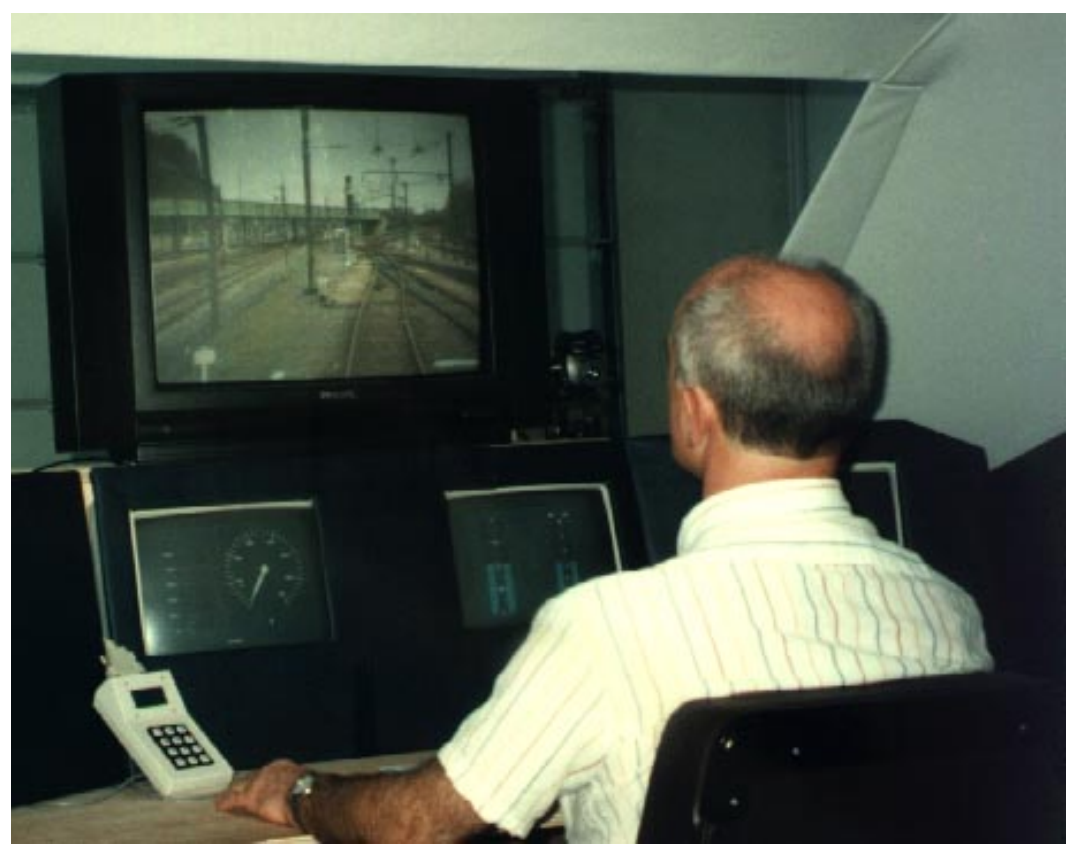

Figure 3 : The simulator

\subsection{The Train Simulator}

The advantage of the simulator is that it provides an experimental site for reproducing the driving cab with its principle components [15] as well as the main environmental parameters which might influence the driving activity such as the forward movement of the rails, ambient sounds, etc. The variable configuration of this simulator also integrates all the new control and informational devices in relation with the new set of auditory signals chosen by the train drivers.

\subsection{The Scenario}

We have chosen a special scenario to test the set of auditory signals chosen by each train driver in a simulated context, as recommended by Maline [9]. During this scenario the train drivers had to:

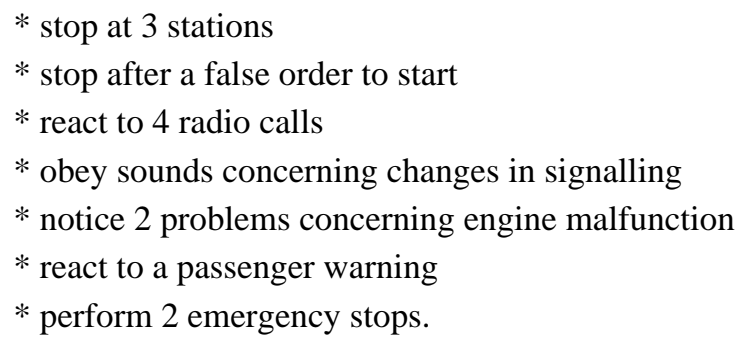

\subsection{Evaluation}

During the realisation of the scenario, 2 cameras recorded the different actions of the driver and his eye movements. With the simulator we have recorded pertinent indicators, selected in agreement with the work group, such as the real speed, the indicated speed, the number of actions, the action realised with the main command to regulate the speed, etc. You can see for example the speed imposed, the speed realised and the moment when the sound was played for one driver in Figure 4. 


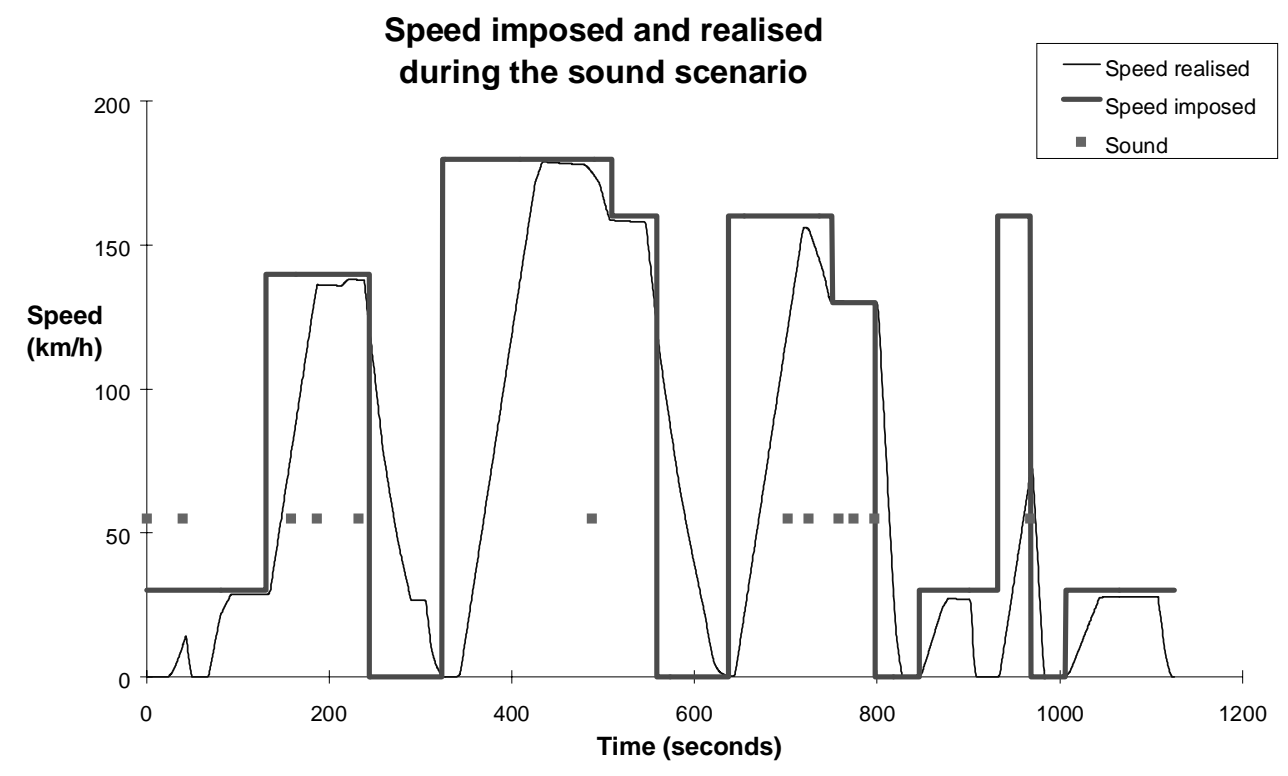

Figure 4 : Speeds realised and speeds imposed for one driver during the scenario with sounds

For a class 1 alarm, which does not necessarily require an action or a visual consultation, we have simply verified that they were indeed detected and that there were no consequences on the driving task.

For the three other classes, we have analysed the type of reaction induced by the sound and measured the time to realise the appropriate action and the time to see the visual information. For technical reason, one of the 12 subjects subject was forced to stop before the end of the experiments.

\subsection{Results}

A set of variance analyses (ANOVA) was conducted to test the effect of the sound class and of the subjects on alarm response measures (time to realise the action, time to see the visual information, and the difference between the time to see the visual information and the time to realise the action).

Concerning the time to realise the appropriate action (Figure 5), the data analyses show an high significant difference (***: $\mathrm{p}<0.001)$ between class 2 sounds (33 measures) and class 4 sounds (33 measures) and a significant effect between class 3 sounds ( 11 measures) and class 4 sounds $(*: p<0.05)$.

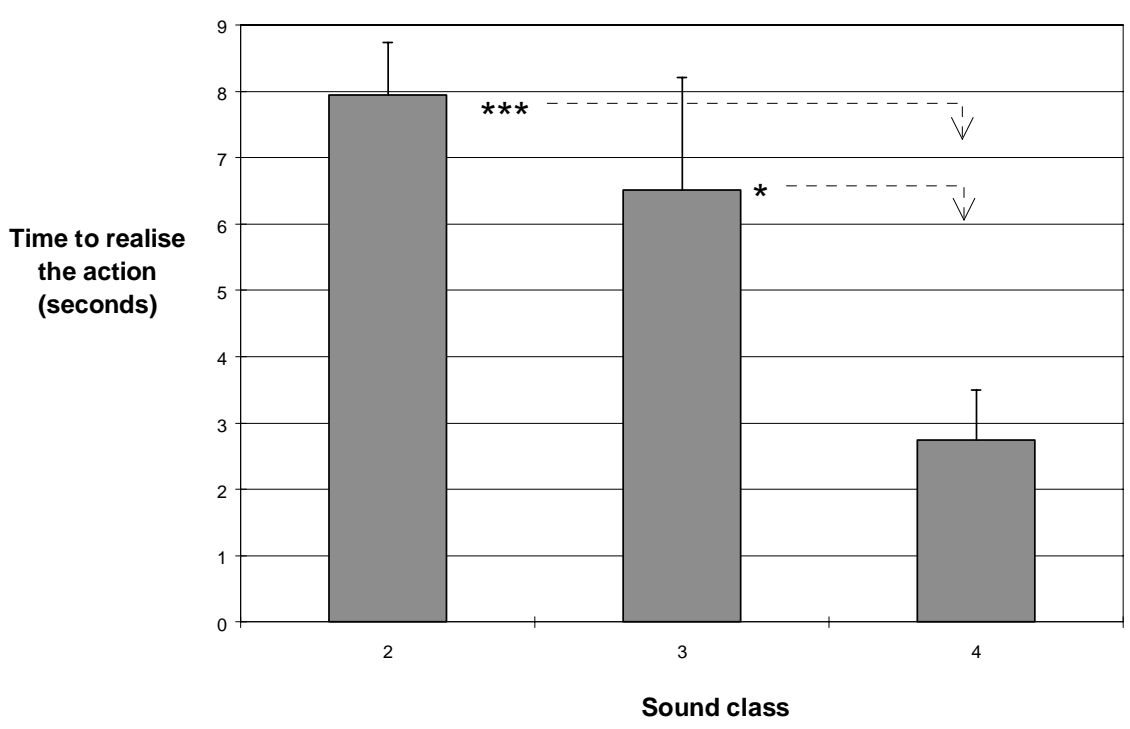

Figure 5 : Mean times to realise the appropriate action $( \pm$ SD) concerning the different classes of sounds, for the 11 drivers. ANOVA $(* * *: p<0.001 ; *: p<0.05)$. 
Concerning the time to see the visual information (Figure 6), the data analyses show a significant difference between class 2 sounds and class 4 sounds $(*: p<0.05)$. There is no significant effect concerning the different subjects(NS).

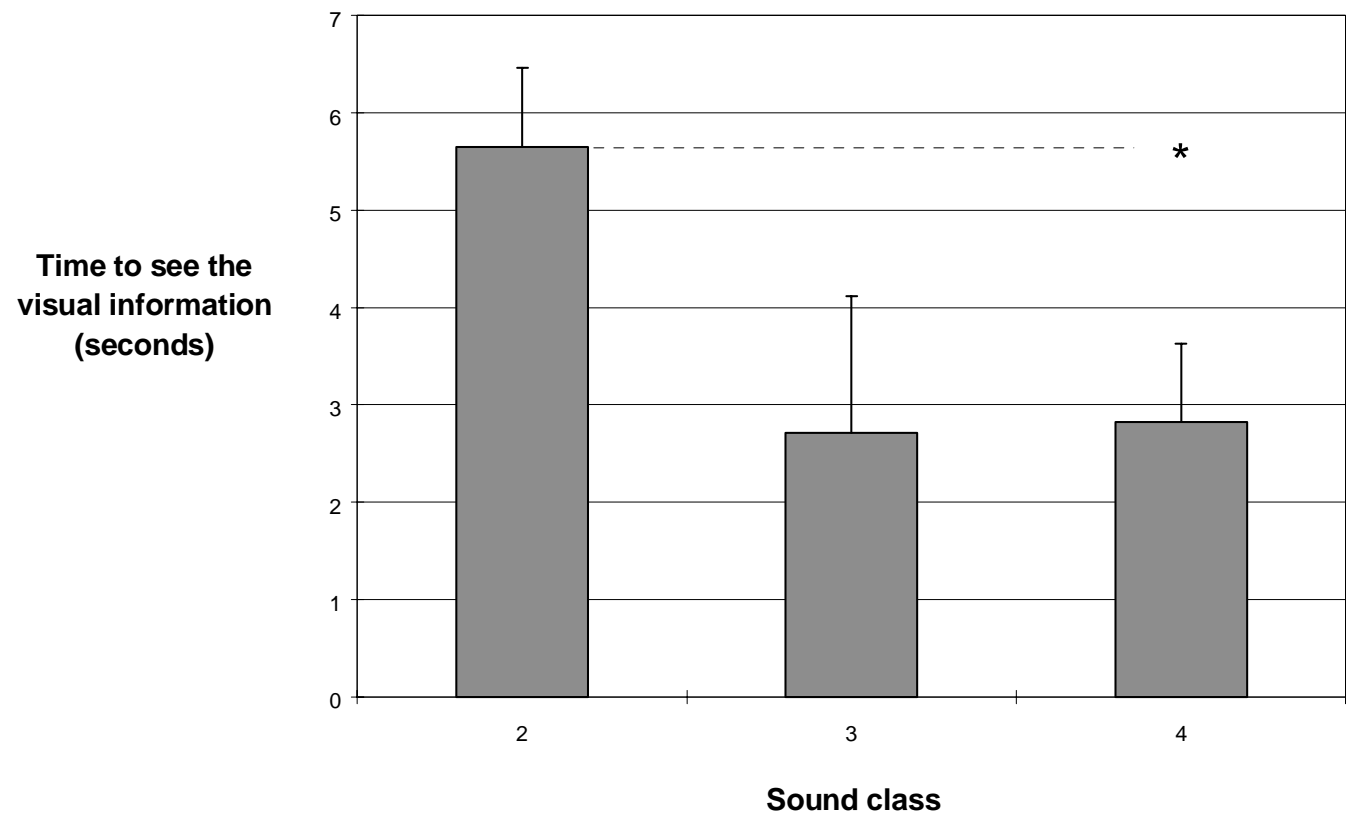

Figure 6 : Mean times to see the visual information $( \pm$ SD) concerning the different classes of sounds, for the 11 drivers. ANOVA $(*: \mathbf{p}<0.05)$.

Concerning the difference between the time to see the visual information and the time to realise the appropriate action (Figure 7), the data analyses show an high significant difference between class 2 and class 4 sounds $(* * *: p<0.001)$, and a significant difference between class 2 and the two other classes $(*: p<0.05)$. There is no significant effect concerning the different subjects(NS).

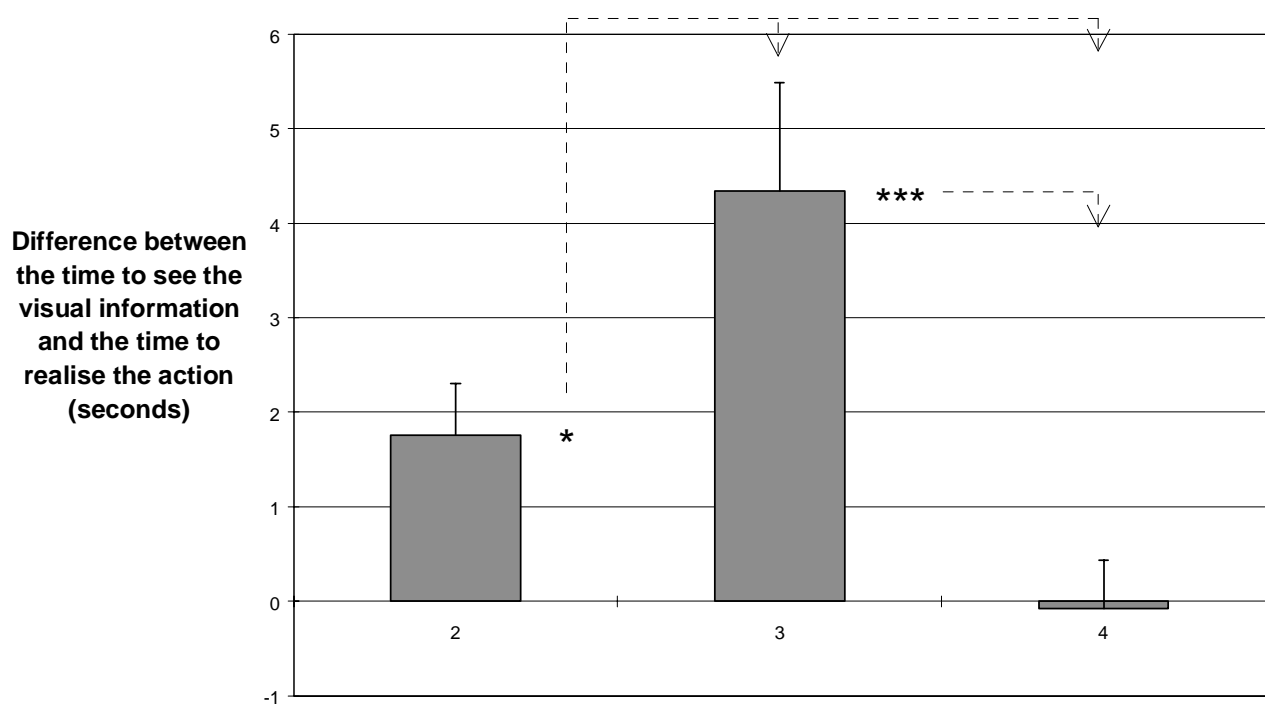

Sound class

Figure 7 : Means differences between the time to see the visual information and the time to realise the appropriate action $( \pm \mathrm{SD})$, concerning the different sound classes for the 12 drivers. ANOVA $(* * *$ : $\mathbf{p}<0.001 ; *: \mathbf{p}<0.05)$. 
These different analyses seem to verify that the differences between 3 classes of new sounds is significant in relation with the appropriate actions induced (action or visual consultation). Moreover, it would verify that these actions are coherent in relation with the driving activity. Indeed :

Class 4 sounds are characterised by the shorter time to realise the action and to see the visual information. These two types of responses induced by the sound are generally simultaneous. It is very coherent because this class concerns sounds which indicate a danger or an accident and the situation needs a very quick and appropriate action.

For class 3 sounds, the time to see the visual information is shorter, but the time to realise the action is longer than for class 4 . In this case, the train driver is informed that he has done something wrong which he has to correct. So he has to identify and to verify the causes of sounds and to find the most effective things to do, to correct the mistake. Another wrong action could cause security system to make an emergency stop which could have consequences on his career if it is repeated.

For class 2 sounds, the time to realise the action and the time to see the visual information is greater than for class 4 . These two types of responses induced by the sound are generally simultaneous. In this case, there is an action to do because of changes in the signalling. It is important to execute it, but it is not necessary to react quickly because there is a short delay to do it.

\subsection{Discussion}

These results enable us to verify :

* the validity of the functional principle of the auditory system,

* the appropriateness between adopted design logic and the driver stereotypes,

* comprehension simplification as a result of the grouping and organisation of sounds.

Thus, the simulation approach has allowed us to make an initial validation of the new set of sounds for the future high speed train. On the basis of our results and according to Edworthy and Stanton [3] we were able to validate with all the members of the project the fact that we have developed auditory warnings that "sound like what they mean" to the appropriate group of users.

The technical aspects of sound in high speed trains will be taken into account later when the same study will integrate sounds from other countries crossed by the high speed train. Then, when all the technical aspects concerning sounds will be defined as recommended by Robinson and Eberts [13], another evaluation will be necessary. Indeed, as mentioned by Haga [6], we may be confronted with other types of errors, depending on the automatic nature of the actions the drivers do which could result in neglecting a signal or which could influence the driver in his choice by masking the main information.

\section{Conclusion}

The design methodology, described in this paper, presents our experience with a simulation approach defined to develop auditory interfaces in the driving cab of the future high speed train. This method had the merit of associating several partners : designers, ergonomists and operators taking into account different opinions to define the final concept concerning auditory interfaces.

The notion of "field of desirable future activities " defined by Sagot et al. [14] was central to our work. On this basis, we have determined and simulated some conditions of the activity in order to optimise and validate the new auditory interfaces. The simulation approach allows representative end-users provide input into the design, testing and modification sessions that are essential to determine an acceptable solution.

There is now an increasing number of work environments for which auditory displays have to be designed and implemented but ergonomic aspects of sounds must not be neglected. The simulation approach, illustrated in this paper, constitutes a useful solution to have a user centred approach and a co-operative design which takes into account the ergonomic aspects of sounds.

\section{Acknowledgements}

The authors extend their thanks to the SNCF for providing support for this study, in particular M. Lorinquer, M. Raimond and all the French drivers for their participation to the experiment, and all the members of the ERCO team who have actively participated in the realisation of the experiment. 


\section{$7 \quad$ References}

1. Antin J.F., Lauretta D.J., Wolf L.D. The intensity of auditory warning tones in the automobile environment : detection and preference evaluations. Applied ergonomics, 1991, 22.1, 13-19.

2. Edworthy J. The design and implementation of non-verbal auditory warnings. Applied ergonomics 1994; 25(4):202-210

3. Edworthy J., Stanton N. A user centred approach to the design and evaluation of auditory warning signals : 1. Methodology. Ergonomics 1995; 38(11):2262-2280

4. Fidell S. Effectivness of audible warning signals for emergency vehicles. Human factors, 1978, 20(1), $19-26$

5. Foret J. Conditions de travail des conducteurs de train : revue des études physiologiques et psychophysiologiques. Le travail humain, 1987, tome 50, $\mathrm{N}^{\circ} 1, \mathrm{p} 17-34$.

6. Haga S. An experimental study of signal vigilance errors in train driving. Ergonomics, 1984, vol. 27, $\mathrm{n}^{\circ} 7,755-765$.

7. Hellier E., Edworthy J., Dennis I. Improving auditory warning design : Quantifying and predicting the effect of different warning parameters on perceived urgency. Human factors 1993; 35(4):693-706

8. Lazarus H., Höge H. Industrial safety : acoustic signals for danger situations in factories. Applied ergonomics 1986; 17(1):41-46.

9. Maline J. Simuler le travail, une aide à la conduite de projet. Editions de l'ANACT, Montrouge ; 1994, 156 p.

10. Momtahan K., Hétu R., Tansley B. Audibility and identification of auditory alarms in the operating room and intensive care unit. Ergonomics 1993; 36(10):1159-1176.

11. NF X 50-151. Analyse de la valeur, analyse fonctionnelle. Expression fonctionnelle du besoin et cahier des charges fonctionnel. Aux éditions AFNOR, Décembre 1991.

12. Patterson R.D. Guidelines for Auditory Warning Systems on Civil Aircraft. Civil Aviation Authority paper 82017, CAA London, 1983

13. Robinson C., Eberts R. Comparison of speech and pictorial displays in a cockpit environment Human factors, 1987, 29(1), 31-44.

14. Sagot J.C., Gouin V., Lorinquer J.P., Chappet P. The high speed train : an ergonomic approach for the driving cab design. In :World Congress on Railway Research. 16-19 November 1997, Florence (Italy), vol. A, 843-851.

15. Zwolinski P., Sagot JC., Gouin V. La simulation de l'activité comme outil d'aide à la conception et à l'innovation: Application à la conception de la nouvelle commande de régulation de la vitesse des TGV futurs. Actes des 2ème Journées "recherche et ergonomie ", les 9, 10 et 11 Février 1998; Université de Toulouse le Mirail, 71-75 